\title{
ВИКОРИСТАННЯ ЧАСТОТНОГО ПЕРЕТВОРЮВАЧА - ДІЄВИЙ ТА ЗРУЧНИЙ СПОСІБ РЕГУЛЮВАННЯ ШВИДКОСТІ НАСОСНОГО АГРЕГАТУ
}

\author{
Юрченко Олександр Юрійович \\ асистент \\ Сумський національний аграрний університет \\ ORCID: 0000-0002-3047-6654 \\ aleksyurchenko110917@gmail.com \\ Барсукова Ганна Володимирівна \\ кандидат технічних наук, ст. викладач \\ Сумський національний аграрний університет \\ ORCID: 0000-0002-4261-2182 \\ Anna-Barsukova@ukr.net
}

\begin{abstract}
У статті розглянуто систему, що дає можливість автоматизованого керування роботою насосного агрегату за різних режимів роботи. Системою забезпечуються ручний та автоматичний режими керування, що дає змогу переважно за автоматичного режиму керування виключити відсоток відмов через людський фактор. Робота системи базується головним чином на використанні перетворювача частоти, що є основним елементом у системі, яка розглядається, та допоміжних структурних елементів, таких як реле захисту від «сухого ходу», реле для захисту від перепаду тиску в основному та резервному насосах, датчики температури та тиску.

Потреба у постійній високоточній зміні швидкості обертання насосного агрегату здатна бути вирішена за рахунок такої системи, принцип роботи якої полягає у надходженні періодичних, коли це необхідно буде здійснювати, сигналів до перетворювача частоти, який залежно від того, яку швидкість обертання насосного агрегату потрібно досягти, буде регулювати частоту, яка безпосередньо має вплив на швидкість обертання електричного двигуна, що є приводним двигуном для насосного агрегату. У разі наприклад зменшення тиску води у системі через датчики температури та реле перепаду тиску буде подано сигнал до частотного перетворювача, яким буде збільшено частоту електромагнітного поля. За рахунок збільшення частоти і при цьому незмінного числа пар полюсів у електричному двигуні буде досягнуто більшу швидкість обертання електродвигуна, що призведе до збільшення продуктивності насосного агрегату, яким накачується певна кількість рідини, тиск якої заздалегідь визначений та запрограмований як стандартне значення тиску у системі. Збільшивши частоту, а відповідно, і продуктивність насосного агрегату, тиск у системі буде піднято до стандартного значення, після чого насосний агрегат буде здійснювати роботу на звичній для себе швидкості.

Таким чином, будь-які відхилення параметрів системи від робочих є контрольованими та регулюються за рахунок датчиків та реле температури, а також перетворювача частоти, який за рахунок зміни частоти здійснює зміну швидкості обертання i, як наслідок, зміну продуктивності роботи насосного агрегату, що може бути використаний у системах тепло- або водопостачання як житлових будинків, так і промислових підприємств окремо взятих груп споживачів.
\end{abstract}

Ключові слова: насос, частота, струм, обертання, продуктивність, тиск, залежність.

DOI https://doi.org/10.32845/msnau.2021.3.8

Вступ (Introduction). Наносні агрегати через свою поширеність у системах водо- та теплопостачання мають відповідати всім необхідним вимогам для задоволення потреб споживачів.

Нерідко питання водопостачання зводиться до використання багатофунккціональної системи, яка повинна здійснювати безперебійне перекачування рідини, підтримання рівня рідини на конкретному визначеному рівні, сигналізувати про будь-які відхилення від нормованих або запрограмованих значень, що відбуваються у системі, і т. п.

Одним з основних завдань насосних агрегатів, що працюють у системі теплопостачання, наприклад суспільних приміщень, є перекачування води, яка є теплоносієм, зі змінною швидкістю. Це пов'язане з перепадом температури навколишнього середовища, а відповідно, і приміщення, надмірним виділенням парів тощо. У зв'язку із цим виникає потреба в безперебійному автоматизованому режимі керування процесом роботи насосного агрегату, що міг би забезпечити всі вище перераховані функціональні можливості та здатність працювати в автоматизованому режимі, тобто без втручання оператора.

Регулювання продуктивності насосних агрегатів можна здійснювати різними способами.

Забезпечення необхідного гідравлічного режиму у циркуляційних системах регулюванням насосу призводить до додаткової втрати енергії на регулювання. Однак це відбувається за винятком способу частотних регулювань, що дозволяє забезпечити режим роботи насосу із найбільшими ККД (Novosti teplosnabzheniya, 2014).

Таким чином, у джерелі 1 (Novosti teplosnabzheniya, 2014) регулювання частотним перетворювачем представлено як найбільш енергетично ефективний спосіб регулювання насосу за змінних витрат води у приєднаних системах. У роботі встановлено, що за постійних витрат води економічно доцільними $є$ більш точні узгодження гідравлічних характеристик насосу і приєднаних мереж, 
які виробляються за рахунок підбору насосів, обточування робочих коліс або проведення налагоджувальних заходів у мережах.

За результатами аналізу кількох розглянутих способів регулювання у джерелі 2 (Kolpakhchian, Lavronova, 2011) вибрано найефективніший з погляду зниження витрат електроенергії. Для прикладу у роботі виконано розрахунок добових енергоспоживань насосною станцією із трьома насосними агрегатами за різних способів регулювання. За результатами розрахунків здійснено побудову графіків залежності споживаної насосними агрегатами потужності та визначено найефективніший спосіб керування.

Аналіз отриманих результатів показав, що зі збільшенням статичного складника у гідравлічному опорі магістралі відбувається зниження ефективності регулювання продуктивності насосу шляхом зміни частоти обертання. Порівняння витрат електроенергії за регулювання частоти обертання всіх насосних агрегатів і одного насосного агрегату у разі підключення інших до мережі безпосередньо показало, що обидва зі способів мають приблизно рівну енергетичну ефективність. Тому для створення пристрою керування групою насосних агрегатів $€$ можливість застосування одного із перетворювачів замість декількох, що суттєво знизить вартість системи.

Способи регулювання насосів хоч і здатні знизити витрату електричної енергії, але не можуть забезпечити ефективного регулювання. Встановлено, що порівняно більша ефективність забезпечується регулюванням, яке ґрунтується на зміні частоти обертання робочих коліс насосів (Urishev, Beitullaeva, Gayimnazarov, Umirov, 2015).

Один із таких способів, що заснований на зміні частоти обертання робочих коліс насосного агрегату, розглянуто в джерелі 3 (Urishev, Beitullaeva, Gayimnazarov, Umirov, 2015). Така система дає змогу за відхилень технологічного параметра (наприклад, витрат води у напірному трубопроводі) від оптимальних значень, запрограмованих для конкретно визначеної системи, додатково формувати сигнали щодо підвищення або зниження частоти обертання електричного двигуна для того, щоб підтримувати необхідне значення технологічного параметру, яке потрібне для того, щоб мати більш високі значення ККД насосного агрегату.

У роботі 4 (Mirmarine, 2021) проаналізовано регулювання насосних агрегатів за такими способами:

- за сталим тиском;

- за сталою температурою;

- регулювання за постійним перепадом тиску циркуляційної системи;

- пропорційним регулюванням напору.

У роботі розглянуто переваги та недоліки кожного з методів регулювання та визначено, що найбільш ефективним $є$ регулювання за допомогою частотного перетворювача.

Для керування асинхронним двигуном можливе векторне управління. Цей спосіб дає змогу збільшити точність частотного регулювання та застосовується там, де $€$ необхідність підтримання моменту двигуна у разі низьких швидкостей обертання та забезпечити стабілізацію швидкостей у разі стрибків навантажень (Ke, 2016).
У роботах 6 та 7 (Araujo, Ramos, \& Coelho, 2006; Piratla, \& Ariaratnam, 2011) представлено причини виникнення у трубопроводах втрат рідини через нестабільність тиску води у системі. Оцінку динаміки роботи системи водопостачання можна проводити, використовуючи математичні моделі, що можуть бути як лінійними (Price, \& Ostfeld, 2012), так і нелінійними (Price \& Ostfeld, 2013) чи стохастичними (Schwartz, Housh, \& Ostfeld, 2016).

Крім того, керований за частотою електричний двигун має певні особливості, серед яких - час намагнічування та розмагнічування двигуна (Volkov, 2018). У разі відключень електродвигуна вентиляторної або насосної установок можливе обертання ротора та робочого колеса приводного механізму в напрямку, протилежному напрямку обертання в робочому режимі (Shabanov, Pashkin, Ivashkin, 2019). Тому використання частотних перетворювачів $€$ досить актуальним нині. Проте, крім переваг векторного керування асинхронним двигуном, цей спосіб частотного керування має значний недолік, що пов'язаний із високими вимогами до обчислювального пристрою, який його реалізує (Korshunov, Khomyak, Vasilyeva, 2020). Тому показники електроприводів із періодичними навантаженнями оцінюються за допомогою циклічного ККД, що визначається за окремо взятий період одного циклу із зміни навантаження. Періоди роботи двигунів з періодичними навантаженнями зі значними величинами пускового та максимального моментів у режимі недовантаження призводять до зниження енергоефективності (Bibik, 2019). 3 цього приводу у роботі (Bibik, Mazurenko, Shikhnenko, 2019) запропоновано алгоритм із зміни напруги живлення та кутів комутації, що забезпечить максимальні значення ККД за зміни частот обертання. В роботі (Anikin, Burkovsky, Mukonin, Tonn, Trubetskoy, 2021) у разі реалізації закону частотного керування зі стабілізацією кута між струмом обмотки статора та струмозачепленням обмотки ротора видається можливою розробка засобів системи керування. А у разі аналізу методів керування у роботі (Ivanov, Sitas, Richter, 2015) виявлено доцільність використання гідродинамічного способу регулювання продуктивності. Цей же спосіб, а також частотно-регульованих приводів розглянуто у порівняльному аналізі ефективності альтернативних способів регулювання продуктивності насосних агрегатів у роботах (Sitas, Peshk, Richter, 2005; Ivanov, Richter, Sitas V, 2012; Alas, Noulette, 2013).

Формулювання цілей статті (постановка завдання). Автоматизація будь-якого технічного процесу має на меті зменшення затрат праці робітником, скорочення витрат часу на здійснення того чи іншого процесу та безпосередньо покращення протікання такого процесу. У зв'язку із цим слід розглянути схему автоматизованої системи керування роботою насосного агрегату та обґрунтувати параметри, що є фундаментальними та підлягають контролю.

Матеріали і методи досліджень (Materials and Methods). Будь-який насосний агрегат має у своєму складі основні структурні частини.

Потреба в регулюванні насосного агрегату, а саме його продуктивності, за рахунок зміни швидкості 


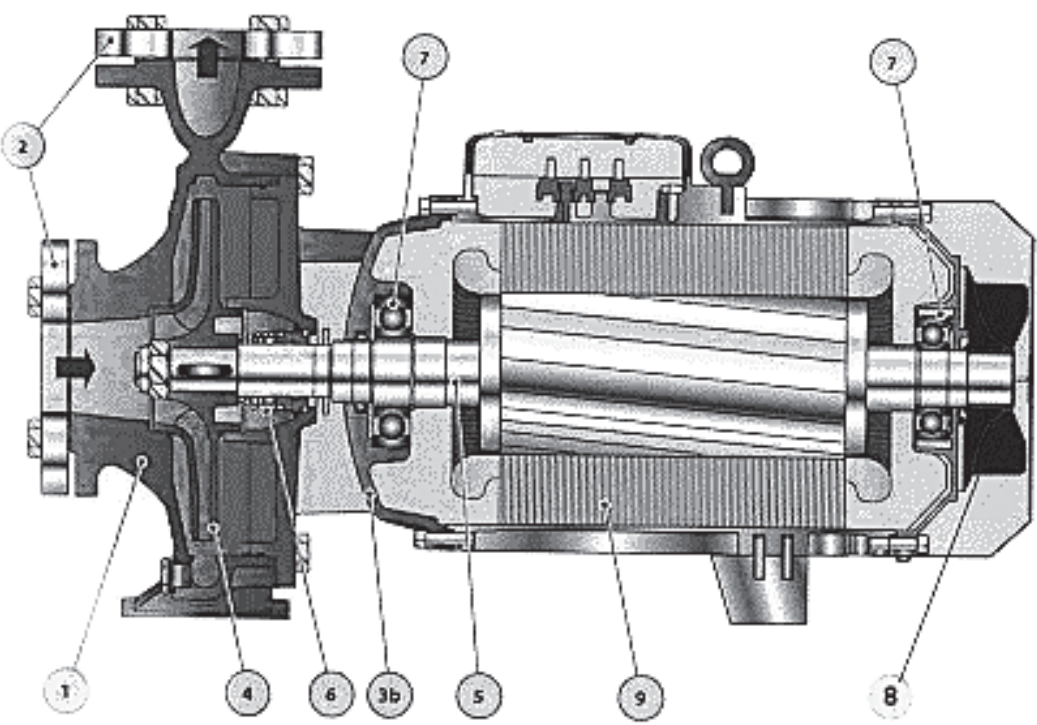

1. Kopnyс насоса

6. Уплотнение вала

2. Ответные фланцыы трубопроводов

7. Подшипники качения

3. Kopnyс sлектромотора

8. Крыльчатка охлаждения мотора

4. Рaбouee кoneco

9. Cтатор

6. Ban эneктромотора

Рис. 1. Будова насосного агрегату:

1 - корпус насосу; 2 - фланці трубопроводу;

3 - корпус електродвигуна; 4 - робоче колесо;

5 - вал електродвигуна; 6 - ущільнення валу; 7 - підшипники:

8 - крильчатка охолодження електродвигуна; 9 - статор

обертання має на меті регулювання саме за рахунок внесення змін у коло керування електродвигуном.

Внесення змін саме у насосний агрегат насамперед веде за собою зміну конструкції насосного агрегату, що може відобразитися на термінах роботи агрегату, які заявлені заводом-виробником такого технологічного обладнання.

Тому внесення змін безпосередньо у коло керування $€$ найбільш ефективним та оптимальним способом регулювання.

У ході дослідження передбачено аналіз роботи системи, що включає у себе:

- основний насос;

- резервний насос;

- частотний перетворювач;

- реле захисту від сухого ходу;

- реле для захисту від перепаду тиску в основному насосі;

- реле для захисту від перепаду тиску в резервному насосі.

Структурну схему досліджуваної системи представлено нижче (рис. 2).

За рахунок вищенаведеної системи є можливість реалізації двох режимів керування насосним агрегатом ручним та автоматичним.

Результати (Results). За нормального режиму роботи системою передбачено роботу лише основного

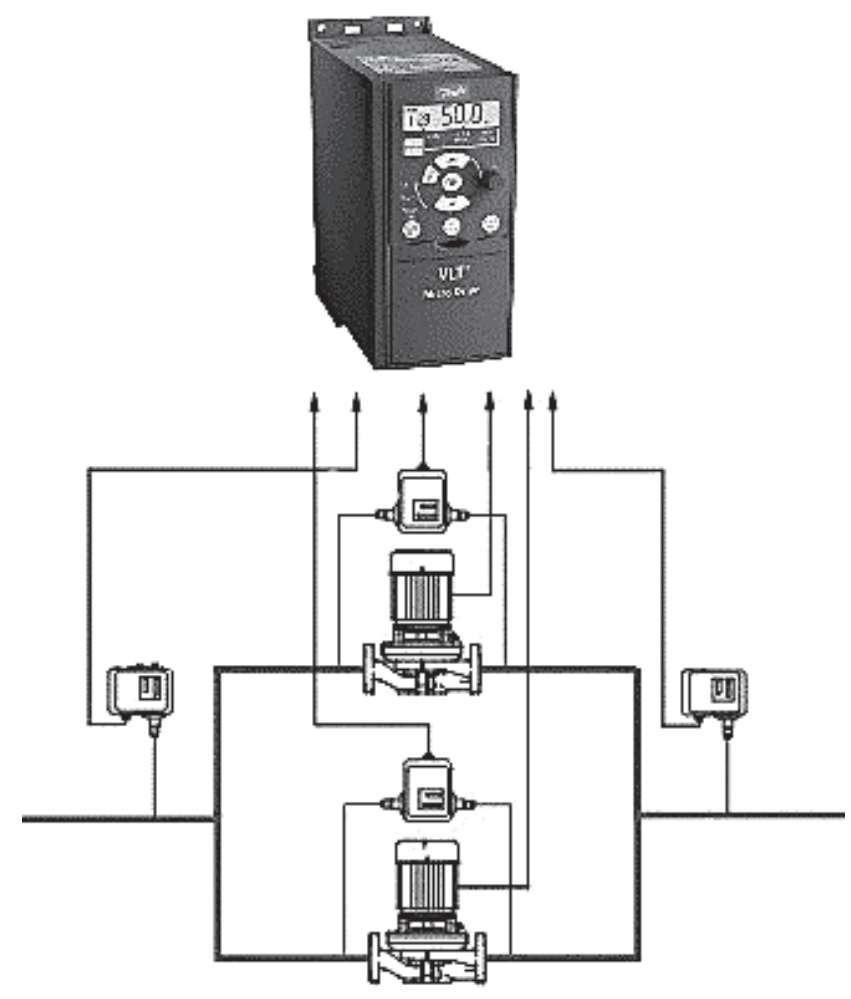

Рис. 2. Структурна схема системи перекачування води 
насосу. Після зниження тиску у системі у піки або за аварійної зупинки основного насосного агрегату буде спрацьовувати реле тиску, що підключене до резервного наносного агрегату.

Система дає змогу вмикання та вимикання насосних агрегатів здійснювати як у ручному, так і в автоматизованому режимах.

Нижче (на рис. 3 та 4) представлено відповідно характеристики регульованого насосного агрегату та робочі точки у разі відкритої та закритої систем.
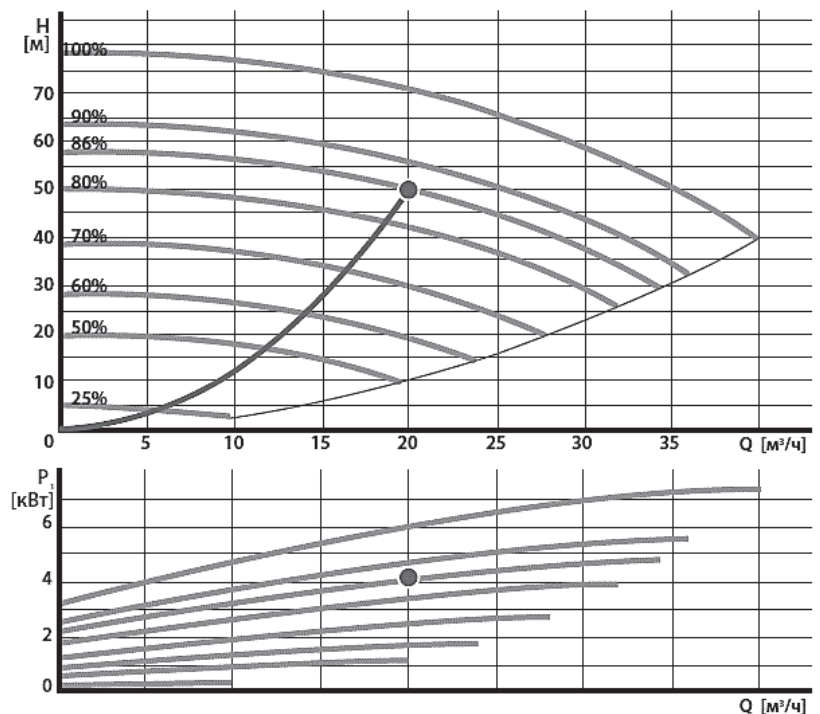

Рис. 3. Характеристики регульованого насосу

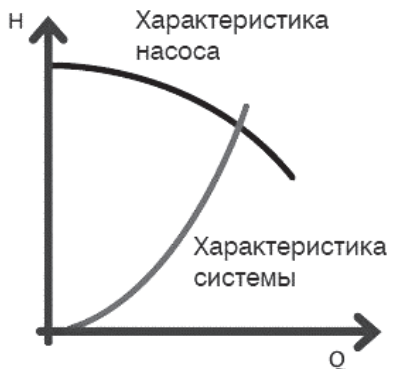

A

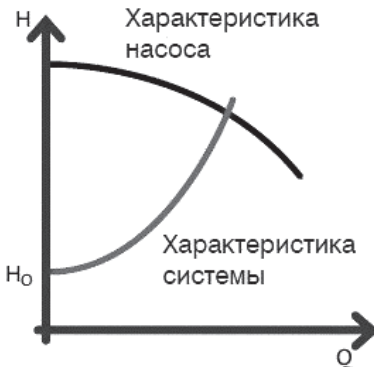

Б
Рис. 4. Робочі точки системи: А - закрита система; Б - відкрита система

Встановлено, що у закритих системах насосний агрегат має працювати ще і на подолання втрат, які присутні у разі протікання по трубопроводах, клапанах та теплообмінниках. Це стосується, перш за все, систем теплопостачання, у яких насосний агрегат використовується для перекачування води, що виступає теплоносієм.

Кількість обертів електричного двигуна залежить від числа пар полюсів.

$$
n=\frac{60 \cdot f}{p}
$$

де $\mathrm{n}$ - синхронна частота обертання;

f - частота струму;

p - кількість пар полюсів.
Змінюючи величину $f$, можна змінювати швидкість обертання без внесення змін у конструкцію як електродвигуна, так і самого насосного агрегату.

Тому зміну швидкості обертання насосного агрегату, а саме електричного двигуна, що є приводом, можна реалізувати внесенням у конструкцію та схему керування агрегатом саме частотного перетворювача. Зміну частоти можна вважати одним із самих ефективних методів регулювання швидкості асинхронного електродвигуна.

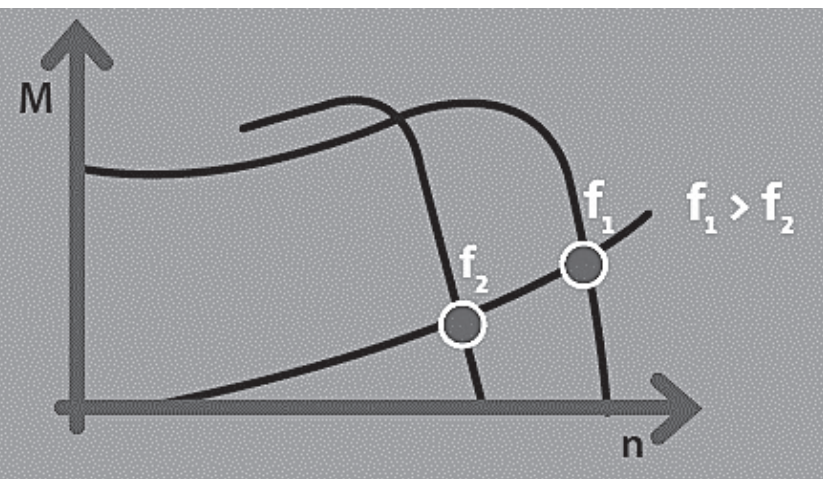

\section{Рис. 5. Зміщення характеристик крутного моменту в електродвигуні}

3 рисунку 5 видно, що зміну швидкості обертання можна досягти за зміни частоти та напруги змінного струму в електричному двигуні. На цій діаграмі показано характеристику крутного моменту (М) як функцію швидкості обертання (n) за двох різних значень частоти та навантаження.

Система, що працює в автоматизованому режимі, здійснює виконання своїх функцій таким чином: якщо температуру теплоносія буде збільшено або зменшено тиск у мережі, то сигнал від відповідного датчика температури буде переданий до частотного перетворювача, який у разі плавного збільшення частоти буде збільшувати швидкість обертання валу електричного двигуна. Відповідно до цього продуктивність насосного агрегату буде збільшено до того моменту, доки не буде досягнуто усталене значення температури або тиску, що були запрограмованими до цього та які не перевищують нормативні значення.

Забезпечення автоматизації процесу відбувається за рахунок датчиків температури та тиску, а реле захисту від сухого ходу дає можливість автоматичної зупинки насосного агрегату за відсутності рідини через технічні причини (витікання, випаровування і т. п.).

Обговорення (Discussion). Дослідження, проведені у роботі (Ledukhovsky, Gorshenin, Zinovyeva, Zinovyeva, 2021) на математичній моделі конденсаційних енергоблоків та теплоелектроцентралей на початковому тиску 12,8 МПа, підтвердили ефект від переходу до частотного регулювання насосів на основі даних за фактично відпрацьований період із урахуванням взаємозв'язку витрати електроенергії для власних потреб і навантаження основного обладнання. За зміни швидкості обертання втрати потужності в перетворювачі частоти істотно перевищують зниження втрат потуж- 


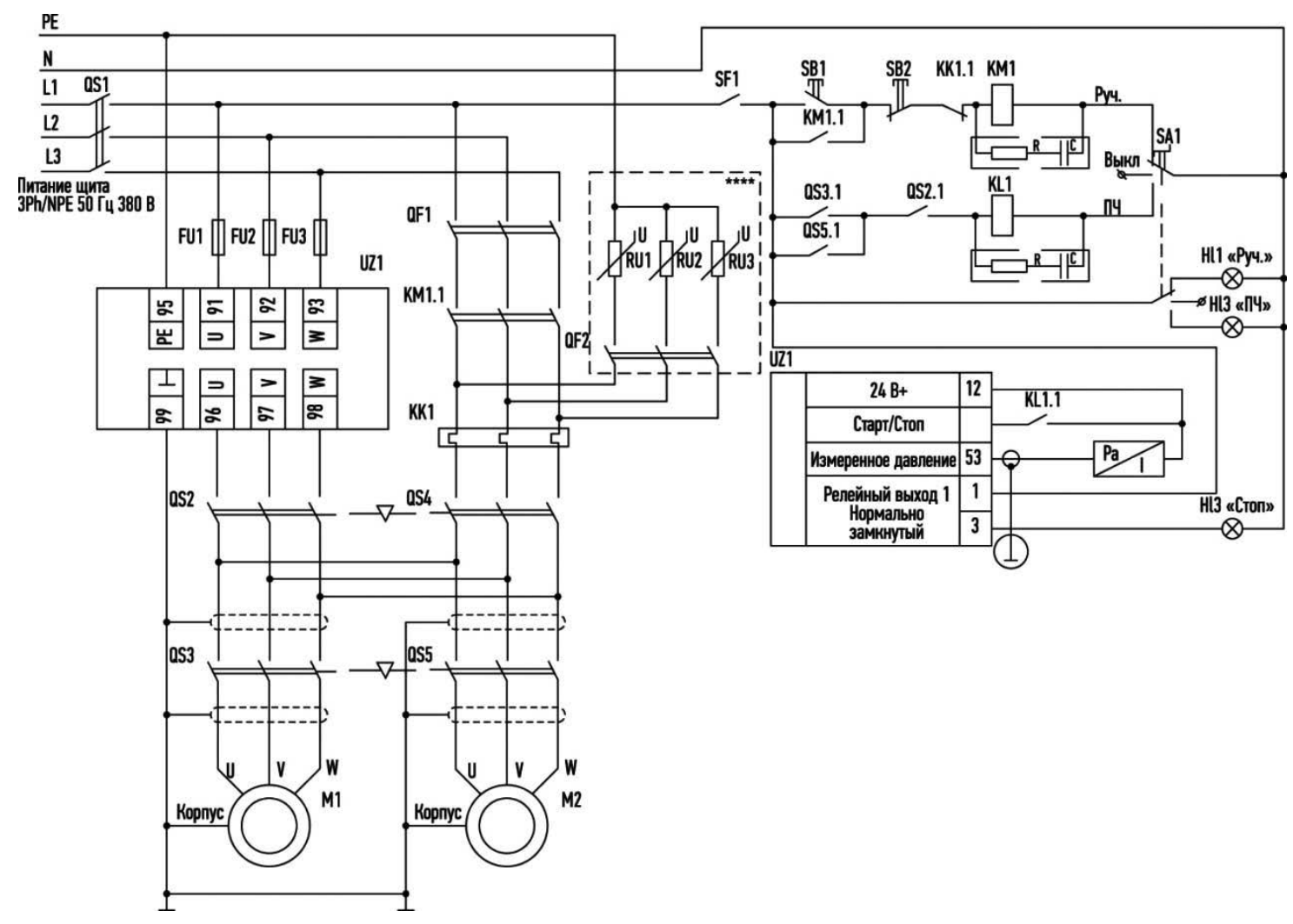

Рис. 6. Схема електрична принципова керування насосом

ності в електродвигуні (Shabanov, Khakimov, Kalimgulov, Sergeenkova, 2019). Тому у разі вибору електродвигунів, керуючись завантаженням їх та швидкістю обертання, потрібно враховувати, крім енергоспоживання, ще і те, що синхронні електродвигуни із постійними магнітами мають порівняно велику вартість, ніж асинхронні електродвигуни, труднощі їх запуску у разі значного моменту інерції, а зниження втрат потужності на перекачування у разі використання перетворювачів частоти може нести за собою підвищення ККД насосу (Goman, Oshurbekov, and Kazakbaev, Prakht, Dmitrievskii, 2020; Shabanov, Khakimov, Kalimgulov, Sergeenkova, 2019).

Аналізом сучасних методів керування насосними агрегатами в роботі (Barabanov, Gavrilov, 2017) виявлено, що частотне регулювання $€$ найбільш сучасним методом керування електричним двигуном і може використовуватися у системах водопостачання, оскільки забезпечує захист насосного агрегату і більш плавне управління, порівнюючи з класичними методами. Однак, не враховуючи довжину трубопроводів у системі керування водопостачанням, досягнення стабільної роботи систем із заданими показниками стійкості не є можливим (Buravchenko, 2016).

У роботі 26 (Shabanov, Sharipova, 2013) наведено аналітичні дані для вибору частоти обертання регульованих насосних агрегатів як з урахуванням необхідних значень продуктивності, так і з урахуванням вимог щодо допустимого діапазону частоти обертання. Нерідко частотно-регульовані електроприводи з трифазними двигунами змінного струму в діапазонах малих та середніх потужностей обладнують перетворювачем частоти, який реалізується у вигляді структури «Некерований випрямляч - автономний інвертор напруги» (Mukonin, Medvedev, Trubetskoy, Tonn, Goremykin, Sitnikov, 2020). 3 метою підвищення ефективності роботи установок насосних агрегатів, крім підключення частотних перетворювачів, можливі підключення ще і компенсаторів (Kopyrin, Portnyagin, Khamitov, 2019), позаяк одним з ефективних способів зниження втрат потужності у разі активно-індуктивного навантаження $€$ компенсація індуктивної складової частини реактивної потужності (Bakshaeva, Suvorova, Cherepanov, 2017).

Таким чином, розглянута у цій роботі система автоматизованого керування роботою насосного агрегату порівняно з іншими системами, представленими у посиланнях, дає змогу реалізації повністю автоматичного режиму роботи. Перевагою системи є виключення похибок або помилок під час керування агрегатом людиною, що реалізується у разі ручного режиму керування.

Зміни, що відбуваються у системі, - зміни тиску, об'єму рідини і т. п. -дублюються за рахунок показання світлової сигнальної арматури та відповідних датчиків. Можливе також підключення за потреби звукової сигналізації.

Автоматизація процесу не потребує зміни конструкції наносного агрегату або приводного електричного двигуна, що є досить важливим у разі, коли насосний агрегат $€$ новим та перебуває на гарантії, а будь-які зміни, внесені в його конструкцію, можуть спричинити зняття агрегату з гарантії.

Висновки (Conclusions). Автоматизація процесу накачування рідини, що виступає у ролі теплоносія для теплопостачання житлових будинків, може бути реалізована за рахунок внесення змін у схему керування 
насосним агрегатом та окремих компонентів. Автоматизований процес здатен забезпечити автономну роботу системи та зупинку насосного агрегату у разі аварійної ситуації без втручання оператора.
3 огляду на те, що зміни стосуються лише додавання окремих компонентів, а не структури насосного агрегату, то система не лише втрачає надійність, а і здатна виключити відхилення у разі ручного режиму керування.

\section{Бібліографічні посилання:}

1. Novosti teplosnabzheniya. (2014). Chastotno-reguliruyemyy privod. Regulirovaniye tsentrobezhnykh nasosov i metody regulirovaniya otpuska tepla $v$ teplovykh setyakh [Variable frequency drive. Regulation of centrifugal pumps and methods of regulation of heat supply in heating networks]. No. 1 (161). Date of access: 20.12.2021 URL: http://www.rosteplo. ru/Tech stat/stat shablon.php?id=3192 (in Russian).

2. Kolpakhchian, P.G., Lavronova, L.I. (2011). Energoeffektivnost' razlichnykh sposobov regulirovaniya elektroprivoda gruppy nasosnykh agregatov [Energy efficiency of various ways of regulating the electric drive of a group of pumping units]. Proceedings of universities. North Caucasian region. Technical science. No. 6. P. 59-63 (in Russian).

3. Urishev, B.U., Beitullaeva, R.Kh., Gayimnazarov, I.Kh., Umirov, A.P. (2015). Vliyaniye regulirovaniya vodopodachi nasosov na vodnoenergeticheskiye parametry nasosnykh stantsiy [Influence of regulation of water supply of pumps on water-energy parameters of pumping stations]. Topical issues of technical sciences: materials of the III Intern. scientific. conf. (Perm, April 2015). Perm: Zebra, 2015. S. 85-86 (in Russian).

4. Mirmarine. (2021). Regulirovaniye rabochikh parametrov nasosov [Regulation of operating parameters of pumps]. Date of access: 09.01.2022. URL: https://mirmarine.net/svm/sudovye-nasosy/1251-regulirovanie-rabochikh-parametrovnasosov (in Russian).

5. Ke, L. (2016). Modelirovaniye i simulyatsiya mashiny dlya ispytaniya na ustalost' nasosov s reguliruyemoy chastotoy International Journal of Engineering, Transactions A: Basics. 29(1). P. 92-102. DOI: 10.5829/idosi.ije.2016.29.01a.13.

6. Araujo, L.S., Ramos, H. \& Coelho, S.T. (2006). Kontrol' davleniya dlya minimizatsii utechek v upravlenii sistemami vodosnabzheniya [Pressure Control for Leakage Minimisation in Water Distribution Systems Management]. Water Resources Management. 20(1). P. 133-149. DOI: 10.1007/s11269- 006-4635-3 4 (in Russian).

7. Piratla, K.R. \& Ariaratnam, S.T. (2011). Criticality Analysis of Water Distribution Pipelines. Journal of Pipeline Systems Engineering and Practice. 2(3). P. 91-101. DOI: 10.1061/(asce)ps.1949-1204.0000077.

8. Price, E. \& Ostfeld, A. (2012). Successive Linear Programming Scheme for Optimal Operation of Water Distribution Networks World Environmental and Water Resources Congress. P. 2964-2970. DOI: 10.1061/9780784412312.2976.

9. Price, E. \& Ostfeld, A. (2013). Iterative Linearization Scheme for Convex Nonlinear Equations: Application to Optimal Operation of Water Distribution Systems. Journal of Water Resources Planning and Management. 139(3). P. 299-312. DOI: 10.1061/(asce)wr.1943-5452.0000275.

10. Schwartz, R., Housh, M. \& Ostfeld, A. (2016). Limited Multistage Stochastic Programming for Water Distribution Systems Optimal Operation. Journal of Water Resources Planning and Management. 142(10), 06016003. DOI: 10.1061/ (asce)wr.1943-5452.0000687.

11. Volkov V.A. (2018). Optimizatsiya vremen namagnichivaniya i razmagnichivaniya [Optimization of magnetization and default times]. "Electrotechnika ta electroenergetika". No. 4. P. 17-29. DOI: 10.15588/1607-6761-2018-4-2 (in Russian).

12. Shabanov, V.A., Pashkin, V.V., Ivashkin, O.N. (2019). Sposob podkhvata elektroprivoda ventilyatsionnykh i nasosnykh ustanovok pri obratnom vrashchenii rabochego kolesa [Method for cooking up the electric drive of ventilation and pump units with reverse rotation of the impeller]. Electrical and data processing facilities and systems. 15(1) P. 26-32. DOI: 10.17122/1999-5458-2019-15-1-26-32 (in Russian).

13. Korshunov, A., Khomyak, V., Vasilyeva, I. (2020). Frequency-current method of controlling an asynchronous threephase motor [Frequency-current method of controlling an asynchronous three-phase motor]. Transactions of the Krylov State Research Centre. 394(4): 129-136. DOI: 10.24937/2542-2324-2020-4-394-129-136 (in Russian).

14. Bibik, O.V. (2019). Vyznachennya khodiv pered proektuvannyam asynkhronnykh pryvodiv pislya zmin [Determination of travels before the design of asynchronous drives in the wake of changes]. Bulletin of NTU "Kharkiv Polytechnic Institute". Series: Electrical machines and electrical engineering. No. 1329 (4). P. 94-98. DOI: 10.20998/2409- 9295.2019.4.14 (in Ukrainian).

15. Bibik, O.V., Mazurenko, L.I., Shikhnenko, M.O. (2019) Formuvannya kharakterystyk robochykh rezhymiv ventyl'noinduktornykh dvyhuniv z periodychnym navantazhennyam [Formation of characteristics of operating modes of valveinduction motors with periodic loading]. Electrical engineering and electromechanics. No. 4. P. 12-16. DOI: https://doi.org/1 0.20998/2074-272X.2019.4.02 (in Ukrainian).

16. Anikin, S.V., Burkovsky, V.L., Mukonin, A.K., Tonn, D.A., Trubetskoy, V.A. (2021). Sposob vektornogo chastnogo upravleniya asinkhronnym elektroprivodom [Method for vector private control of asynchronous electric drive]. Voronezh State Technical University Bulletin. T. 17. No. 5. 2021. P. 98-103. DOI: 10.36622/VSTU.2021.15.5.014 (in Russian).

17. Ivanov, V.B., Sitas, V.I., Richter, M. (2015). Otsenka effektivnosti vnedreniya gidromuft dlya regulirovaniya proizvoditel'nosti tsentrobezhnykh nasosov [Evaluation of the effectiveness of the introduction of hydraulic couplings to regulate the performance of centrifugal pumps]. Technological audit and production reserves. No. 1(4). P. 55-60. DOI: 10.15587/2312-8372.2015.47783 (in Russian).

18. Sitas, V.I., Peshk, A., Richter, M. (2005). Konkurentosposobnyy reguliruyemyy privod dlya energetiki [Competitive variable speed drive for power generation]. Energy drink. No. 2. P. 45. (in Russian).

19. Ivanov, V.B., Richter, M., Sitas, V.I. (2012). K voprosu o sravnitel'noy effektivnosti mekhanotronnogo i chastotnoreguliruyemogo privodov [On the question of the comparative efficiency of vacuum and variable frequency drives]. Eastern European Journal of Advanced Technologies. 3/10(57). P. 32-35 (in Russian). 
20. Alas, P., Noulette, E. (2013). Electro Compression a Challenging Alternative: How and Why to Choose a Gas Turbine or an Electric Motor to Drive a Centrifugal Compressor Turbine. Technical Conference GT 2013, June 3-7, 2013, San Antonio, Texas, USA. ASME International. 9 p. DOI: 10.1115/gt2013-94163.

21. Ledukhovsky, G.V., Gorshenin, S.D., Zinovyeva, E.V., Zinovyeva, A.S. (2021). Analiz effektivnosti regulirovaniya pitatel'nykh nasosov izmeneniyem chastoty vrashcheniya rotora dlya elektrostantsiy razlichnogo tipa [Analysis of the efficiency of feed pump control by changing the rotor speed for power plants of various types]. Bulletin of the Ivanovo State Power Engineering University. No. 4. P. 5-14 (in Russian).

22. Goman, V.V. and Oshurbekov, S.Kh. and Kazakbaev, V.M. and Prakht, V.A. and Dmitrievskii, V.A. (2020). Comparison of energy consumption of various electrical motors operating in a pumping unit. Electrical Engineering \& Electromechanics. (1). 16-24. URL: https://doi.org/10.20998/2074-272X.2020.1.03.

23. Shabanov, V.A., Khakimov, E.F., Kalimgulov, A.R., Sergeenkova, E.V. (2019). Issledovaniye zavisimosti KPD elektrodvigatelya i preobrazovatelya chastoty ot koeffitsiyenta zagruzki i chastoty vrashcheniya [Research of the dependence of efficiency of electric motor and frequency converter on loading coefficient and rotation frequency]. Electrical and information complexes and systems. No. 4, т. 15, P. 83-90. DOI: 10.17122/1999-5458-2019-15-4-83-90 (in Russian).

24. Barabanov, V.G., Gavrilov, D.P. (2017). Razrabotka i issledovaniye sistemy upravleniya nasosnoy ustanovkoy [Development and research of a control system for a pumping unit]. Bulletin of SUSU. Ser. Mechanical engineering. T. 17, No. 2. P. 11-19. DOI: 10.14529/engin170202 (in Russian).

25. Buravchenko, K.O. (2016). Doslidzhennya ta analiz dynamiky protsesu rehulyuvannya nasosnym ahrehatom. Tekhnolohycheskyy audyt y rezervy proyzvodstva [Preliminary and analysis of the dynamics of the process of regulation by the pumping unit]. Technological audit and production reserves. T. 3, No. 2 (29). P. 15-19. DOI: 10.15587/2312-8372.2016.71878 (in Ukrainian).

26. Shabanov, V.A., Sharipova, S.F. (2013). Trebovaniya k chastote vrashcheniya magistral'nykh nasosov pri chastotnoreguliruyemom elektroprivode [Requirements to the speed of rotation of main pumps with a frequency-controlled electric drive]. Electrical and information complexes and systems. No. 3. T. 9. P. 42-46 (in Russian).

27. Mukonin, A.K., Medvedev, V.A., Trubetskoy, V.A., Tonn, D.A., Goremykin, S.A., Sitnikov, N.V. (2020). Povysheniye nadezhnosti sistem avtomaticheskogo upravleniya tekhnologicheskimi protsessami [Increasing the reliability of automatic control systems of technological processes]. Voronezh State Technical University Bulletin. T. 16. No. 4. P. 56-63. DOI: 10.25987/VSTU.2020.16.4.007 (in Russian).

28. Kopyrin, V.A., Portnyagin, A.L., Khamitov, R.N. (2019). Puti povysheniya effektivnosti ustanovok elektrotsentrobezhnykh nasosov dobychi nefti [Ways to increase the efficiency of electric centrifugal pumps for oil production]. Bulletin of the Tomsk Polytechnic University. Engineering of georesources. T. 330. No. 11. 155-162. DOI: 10.18799/24131830/2019/11/2361 (in Russian).

29. 1860-2014. IEEE Guide for Voltage Regulation and Reactive Power Compensation at $1000 \mathrm{kV}$ AC and Above. DOI: 10.1109/IEEESTD.2014.6861419.

30. Bakshaeva, N.S., Suvorova, I.A., Cherepanov, V.V. (2017). Voltage quality improving in power distribution networks with abruptly variable load by application of reactive power series compensation devices. International Conference on Industrial Engineering, Appli cations and Manufacturing (ICIEAM). St. Petersburg, Russia, 16-19 May 2017. DOI: 10.1109/ICIEAM.2017.8076281.

Yurchenko O. Y., Assistant, Sumy National Agrarian University, Sumy, Ukraine

Barsukova H. V., PhD, Sumy National Agrarian University, Sumy, Ukraine

\section{Using a frequency converter is an effective and convenient way to control the speed of the pump unit}

The article considers a system that allows automated control of the pump unit in different operating modes. The system provides manual and automatic control modes, which allows, mainly in automatic control mode, to eliminate the percentage of failures due to the human factor. The operation of the system is based mainly on the use of a frequency converter, which is the main element in the system under consideration, and auxiliary structural elements, such as relays for protection against "dry running", relays for protection against pressure drops in the main and backup pumps, sensors temperature and pressure.

The need for constant high-precision change of the speed of the pump unit can be solved by such a system, the principle of which is to receive periodic, when necessary, signals to the frequency converter, which, depending on the speed of the pump unit to be achieved, will regulate the frequency that directly affects the speed of the electric motor, which is the drive motor for the pump unit. For example, when the water pressure in the system decreases, a signal will be sent to the frequency converter via the temperature sensors and the differential pressure switch, which will increase the frequency of the electromagnetic field. By increasing the frequency and, at the same time, the constant number of pole pairs in the electric motor, a higher motor speed will be achieved, which will increase the productivity of the pump unit, which pumps a certain amount of fluid whose pressure is predetermined and programmed as a standard pressure system. By increasing the frequency and, consequently, the performance of the pump set, the pressure in the system will be raised to the standard value, after which the pump unit will run at its usual speed.

Thus, any deviations of the system parameters from the working ones are controlled and regulated by sensors and temperature relays, as well as a frequency converter, which by changing the frequency changes the speed and, consequently, changes the performance of the pump unit, used in heat or water supply systems of both residential buildings and industrial enterprises of individual consumer groups.

Key words: pump, frequency, current, rotation, performance, pressure, dependence.

Дата надходження 16.09.2021 p. 